\title{
PREVALENCE AND PATTERN OF SUBSTANCE USE AMONG UNDERGRADUATE MEDICAL STUDENTS AT BIRAT MEDICAL COLLEGE AND TEACHING HOSPITAL
}

\author{
Rajesh Kumar Shah ${ }^{1 *}$, Sidarth Timsinha ${ }^{2}$, Sanjib Kumar Sah ${ }^{3}$, Umesh Kumar Mehta ${ }^{4}$, Raju Kumar Chaudhary ${ }^{4}$
}

\begin{abstract}
Affiliation
1. Lecturer, Department of Forensic Medicine, Birat Medical College and Teaching Hospital, Nepal.

2. Associate Professor, Department of Forensic Medicine, Birat Medical College and Teaching Hospital, Nepal.

3. Lecturer, Department of Anatomy, Birat Medical College and Teaching Hospital, Nepal.

4. Assistant Professor, Department of Anatomy, Birat Medical College and Teaching Hospital, Nepal.

5. Assistant Professor, Department of Anatomy, Birat Medical College and Teaching Hospital, Nepal.
\end{abstract}

\section{ARTICLE INFO}

Received : 09 February, 2021
Accepted : 25 March, 2021
Published : 15 June, 2021

(C) Authors retain copyright and grant the journal right of first publication with the work simultaneously licensed under Creative Commons Attribution License CC - BY 4.0 that allows others to share the work with an acknowledgment of the work's authorship and initial publication in this journal.

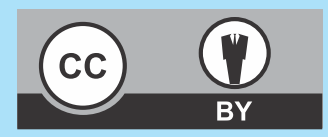

\section{ORA 241}

DOI: https://doi.org/10.3126/bjhs.v6i1.37644

\section{* Corresponding Author \\ Dr Rajesh Kumar Shah Lecturer \\ Department of Forensic Medicine} Birat Medical College and Teaching Hospital, Nepal Email:drrajeshshahbmc@gmail.com ORCID: https://orcid.org/0000-0002-4207-8709

\section{Citation}

Rajesh Kumar Shah, Sidarth Timsinha, Sanjib Kumar Sah, Umesh Kumar Mehta, Raju Kumar Chaudhary. Prevalence and Pattern of Substance use Among Undergraduate Medical Students at Birat Medical College and Teaching Hospital. BJHS 2021;6(1)14. 1392 - 1395.

\section{ABSTRACT}

\section{Introduction}

Medical students encounter a constant pressure of academic and clinical activities, as well as easy access to drugs which could enable them to use different substances. Medical students who use substances can endanger others by losing sound judgment, failing to take responsibility, and causing harm to service recipients.

\section{Objective}

The study was aimed to find out the prevalence and pattern of substance use among undergraduate medical students of Birat Medical College and Teaching Hospital, Nepal.

\section{Methodology}

This hospital based cross sectional study was carried out from January 2021 to February 2021 at Birat Medical College and Teaching Hospital, Morang Nepal. A total of 207 subjects were included in the study, which was selected using convenience sampling. All participants were given a self-prepared semi-structured pre-tested questionnaire in order to gather information about their sociodemographic profile and pattern of substance use.

\section{Result}

The overall prevalence of substance use among students of BMCTH was 59 (28.50\%) ( $n=207)$. Males were significantly associated with substance use than females $(P<0.001)$. Prevalence of substance use were maximum among final year students 26 (76.47\%). The most common used substance was alcohol 49 (83.05\%) followed by tobacco smoking 24 (40.67\%) and cannabis 11 (18.64\%). Curiosity of experience 39 (35.77\%) and seeking pleasure 19 (17.43\%) were the main reason of substance use among students.

\section{Conclusion}

In this study students were found to be involved in some form of substance use, with many of them initiating after enrolling in medical school. Majority of students used for the sake of fun which they use as a source of entertainment to deviate their minds from the pressure of studies.

\section{KEYWORDS}

Pattern, medical, substance use, prevalence 


\section{INTRODUCTION}

Medical school is a critical transitional period in students lives, during which they may begin to consume alcohol, tobacco and other substances. ${ }^{1}$ Medical students who use substances may endanger others by losing sound judgment, failing to take responsibility and causing harm to service recipients. Medical students have a continuous burden of academic and clinical activities and have easy access to drugs that might influence the students to use the substances. ${ }^{2}$ Rates of substance use reported by different studies vary globally. ${ }^{3,4}$ Literature revealed that physicians, dentist, nurses have far higher rates of dependence, uncontrolled substances such as opioids, stimulants, sedatives than other professionals of compared educational achievements e.g. lawyers. ${ }^{5}$ Research shows the estimated prevalence rate of substance abuse among students is around 20 to 40 percent worldwide. ${ }^{6,7}$ In Nepal, 50 to $60 \%$ of medical students are estimated to be substance abusers. ${ }^{8}$ The reasons for such a high prevalence among medical and dental students are numerous and complex, including exposure to a variety of academic, social and economic stressors that may affect learning ability and academic performance. ${ }^{9}$ Medical schools should train medical students to understand the risk inherent in the use of addictive substances because, in the future, they will have to prevent, diagnose and treat substance use and abuse by their patients. The importance of studies like this one is more significant as there is lack of cumulative evidence related to substance use. Therefore, the study is undertaken to find out the prevalence and pattern of substance use among undergraduate medical students of Birat Medical College and Teaching Hospital, Nepal.

\section{METHODOLOGY}

This is a descriptive cross-sectional study conducted among the undergraduate students of Birat Medical College and Teaching Hospital, Morang Nepal. The study was conducted over one month duration from January 2021 to February 2021. The study was approved by Institutional Review Committee of BMCTH (Ref: IRC-PA-095/2077-78). For possible ethical concerns, the study protocol was discussed among the students and facilitating faculty. All possible measures were taken to ensure the confidentiality of all participants. Written informed consent was obtained from all the participating subjects. The sample consisted of a total of 207 subjects selected through convenience sampling. Inclusion criteria constituted all basic and clinical undergraduate medical students who provided informed consent. A self-prepared semi-structured questionnaire administered in English language was used to conduct this study. The questionnaire was created following a comprehensive analysis of the literature, as well as discussions among investigators. Participants were asked to return the filled-up questionnaire to investigators within 20 minutes. The first part of the questionnaire contained the socio-demographic profile of the students. The second part gathered information about type of substance use, frequency of use, reason of initiation source of drugs etc. Substances included were alcohol, cannabis, stimulants, sedatives, tranquilizers, opium, cocaine, hallucinogens, inhalants (volatile agents) and tobacco (including cigarettes and snuff). All the descriptive data was entered and analyzed in Statistical Package for Social Sciences (SPSS 21.0 version).

\section{RESULTS}

The overall prevalence of substance use among students of Birat Medical College \& Teaching Hospital was 59 (28.50\%). Males were more associated with substance use than females. This association of males with substance use was statistically significant $(P<0.001)$. Out of total participants, 157 (75.84\%) were Nepalese national and 50 (24.15\%) were Indian; 106 (51.20\%) were males and 101 (48.79\%) were females. Age of the participants ranged from 16-27 years with mean age of $21.95 \pm 1.99$ years. Among them, majority belonged to the age group 20-23 years 146 (70.53\%). Most of the participants were Hindu by religion 186 (89.85\%) and had a dual family type 172 (83.09\%).Majority 202 (97.58\%) of the participants resided in campus hostel.

\begin{tabular}{|c|c|c|}
\hline & Frequency (n) & Percentage (\%) \\
\hline \multicolumn{3}{|l|}{ Age group: (Years) } \\
\hline $16-19$ years & 15 & 7.24 \\
\hline 20-23 years & 146 & 70.53 \\
\hline $24-27$ years & 45 & 21.73 \\
\hline$>27$ years & 1 & 0.48 \\
\hline \multicolumn{3}{|l|}{ Sex } \\
\hline Male & 106 & 51.20 \\
\hline Female & 101 & 48.79 \\
\hline \multicolumn{3}{|l|}{ Religion } \\
\hline Hindu & 186 & 89.85 \\
\hline Buddhist & 5 & 2.41 \\
\hline Muslim & 8 & 3.86 \\
\hline Christian & 7 & 3.38 \\
\hline Others & 1 & 0.48 \\
\hline \multicolumn{3}{|l|}{ Nationality } \\
\hline Nepalese & 157 & 75.84 \\
\hline Indian & 50 & 24.15 \\
\hline \multicolumn{3}{|l|}{ Family type } \\
\hline Dual Type & 172 & 83.09 \\
\hline Single family & 33 & 15.94 \\
\hline Step parent & 2 & 0.96 \\
\hline \multicolumn{3}{|l|}{ Year of MBBS } \\
\hline First year & 69 & 33.33 \\
\hline Second year & 52 & 25.12 \\
\hline Third year & 52 & 25.12 \\
\hline Fourth year & 34 & 16.42 \\
\hline \multicolumn{3}{|l|}{ Residence } \\
\hline Campus Hostel & 202 & 97.58 \\
\hline Home with parents & 5 & 2.41 \\
\hline
\end{tabular}

Prevalence of substance use were maximum among final year students 26 (76.47\%) than first year $16(23.18 \%)$, second year $12(23.07 \%)$ and third year students 4 (7.69\%). Prevalence of substance use was more among those staying in campus hostels $58(98.30 \%)$ than those living at own homes. Out of 
the most common used substance was alcohol 49 (83.05\%) followed by cigarette smoking $24(40.67 \%)$ and cannabis 11 (18.64\%). Out of those doing substance use, 20 (33.89\%) of the students were poly-substance users. Only 1 (1.69\%) student reported the use of opioids.

\begin{tabular}{|c|c|c|c|}
\hline \multirow[b]{2}{*}{ Categories } & \multicolumn{2}{|c|}{ Sex $(n=207)$} & \multirow[b]{2}{*}{ Total } \\
\hline & Male & Female & \\
\hline Tobacco smoking & 23 & 1 & $24(40.67 \%)$ \\
\hline Alcohol & 36 & 13 & 49(83.05\%) \\
\hline Cannabis & 10 & 1 & $11(18.64 \%)$ \\
\hline Others & 0 & 1 & $1(1.69 \%)$ \\
\hline Total & 69 & 16 & 85 \\
\hline $\begin{array}{l}\text { Others: (Opioids, LSD, } \\
\text { amphetamine, Glue sniffing) }\end{array}$ & & & \\
\hline
\end{tabular}

About 22(37.28\%) of students started using substance after joining medical college. Approximately 35 (59.32\%) students started taking substance at age between $17-20$ years.

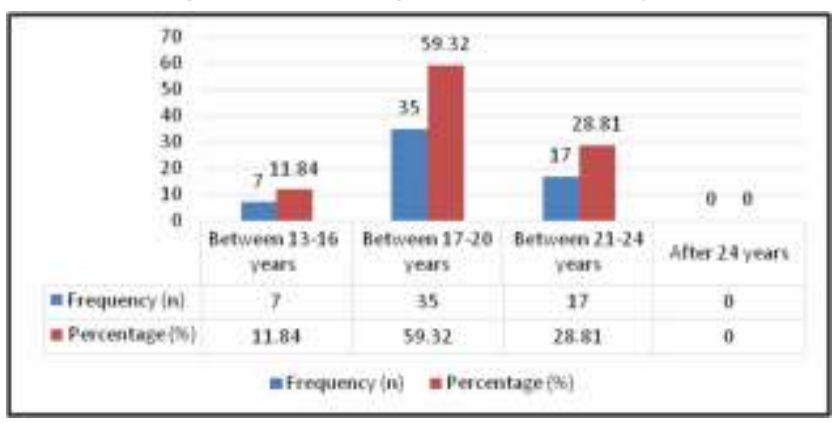

Figure 1: Age at first initiating substance use

The main reason of substance use was due to curiosity of experience 39 (35.77\%) and seeking pleasure 19 (17.43\%). Frustration or stress relief 17 (15.59\%) and personal tragedy $6(5.50 \%)$ were also among the notable causes of substance use.

Table 3. Reasons for initiating substance use among medical students(*Multiple response)

\begin{tabular}{|l|c|}
\hline Reason & $\begin{array}{c}\text { Total frequency } \\
(\%)\end{array}$ \\
\hline Due to curiosity of experience & $39(35.77 \%)$ \\
\hline Peer pressure & $15(13.76 \%)$ \\
\hline Personal tragedy & $6(5.50 \%)$ \\
\hline Failure in love & $3(2.75 \%)$ \\
\hline Academic failure & $2(1.83 \%)$ \\
\hline Stress relief & $17(15.59 \%)$ \\
\hline Feeling of pleasure & $19(17.43 \%)$ \\
\hline Social obligation & $4(3.66 \%)$ \\
\hline Can't help it, Can't resist & $4(3.66 \%)$ \\
\hline
\end{tabular}

Out of 59 students using substance, 21 (35.59\%) of them had a positive family history of substance use. Majority of the students bought them from local shop 44 (74.57\%) and 23(38.98\%) got from friends.

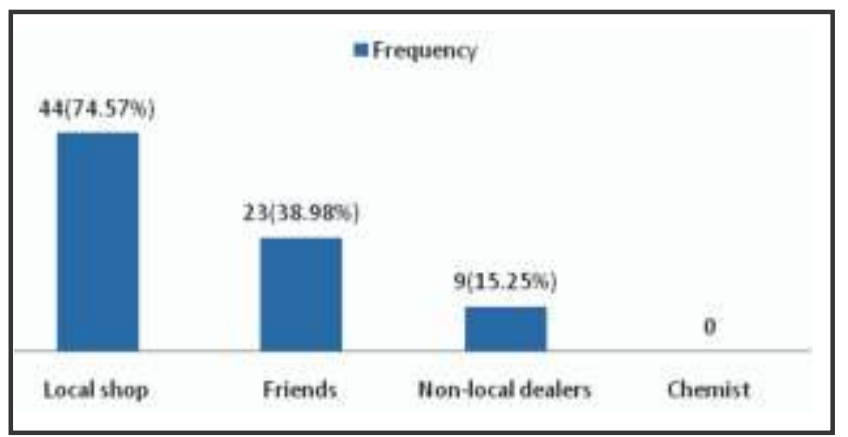

Figure 2: Source of substance use

Among the substance users 7 (11.86\%) students mentioned that were dependent on some substance while 35 (59.32\%) participants wanted to quit in the future.

\section{DISCUSSION}

Substance use is widely recognized as a critical area of concern when it comes to medical students. The present study was undertaken to determine the prevalence and pattern of substance use in medical undergraduate students of different academic stages. The overall prevalence of substance use among the medical students of BMCTH was found to be (28.50\%). This prevalence rate is comparable to an Indian study, which showed a prevalence rate of $24.2 \%$. However various Nepalese studies showed higher prevalence rate compared to our study. ${ }^{2,8,11}$ In our study males were found to have a significantly higher frequency of substance use than females. Multiple studies have confirmed that substance use is associated with gender. ${ }^{12,13}$ However, this finding is not in support to another study where no difference was observed in substance use related to genders. ${ }^{8}$ This male predominance in substance use could be attributed to our social structure, which gives men more freedom, than females. It is widely recognized that adolescent alcohol consumption is primarily a social act. ${ }^{1}$ According to a study from Newcastle, UK, college students had a higher prevalence of drinking and alcohol related disorders than non-college youths. ${ }^{14}$ Medical students are a high-risk group. Alcohol, tobacco and cannabis use, as observed in our study was (83.05\%), (40.67\%) and (18.64\%) respectively. In the same way, a study from Nepal also discovered (60.3\%) medical students using various substances. Among them alcohol $(57.6 \%)$, tobacco $(27.6 \%)$, and cannabis $(12.8 \%)$ were commonly used. ${ }^{2}$ Also, comparable results have been found in another study in Nepal where the use of alcohol, tobacco, and marijuana were $59.6 \%, 28.2 \%$ and $11.9 \%$ respectively. ${ }^{15}$

These patterns of alcohol, tobacco, and cannabis use may reflect Nepalese society's substance use pattern and are recognized as a social sanction. ${ }^{2}$ However, socio-demographic factors, education level, peer pressure, independent lifestyle, stressful activities, psychological factors and many more all have a significant impact on the consumption of these substances. ${ }^{2,8,12}$

It has been widely reported that moving up the educational ladder can have an impact on the use of various substances. ${ }^{15}$ 
In our survey, final year medical students (76.47 \%) used more substances than other years of medical students. In this study, it was observed that medical school is not a typical starting point for alcohol and tobacco use. The use of alcohol and tobacco was established prior to starting medical school, whereas the use of cannabis and opioids began after joining medical school. Experimentation (35.77\%) was one of the major reasons of substance use followed by feeling of pleasure (17.43\%). Similarly, another Nepalese study reported experimentation (42.3\%), stress (19.5\%), and pleasure (15.4\%) as principal causes of substance use. ${ }^{2}$ After starting with alcohol, other drugs are consumed for curiosity, pleasure, or to alleviate psychological stress. It was observed that as students advance up the academic ladder, there has been an increase in substance use. The frequency and prevalence of poly-drug use could be due to high level of stress experienced by students as a result of academic pressure. Therefore, it is critical to educate students about the risks and benefits of substance use during the early stages of their medical careers. This appears to be more important to prevent this worrying situation before they become a qualified doctor.

\section{CONCLUSION}

In this study students were found to be involved in some form of substance use, with many of them initiating after enrolling in medical school. Majority of students used substances for the sake of fun which they use as a source of entertainment to deviate their minds from the pressure of studies. This study might help in education, prevention, screening and policy making relating to the consequences of the substance use for the betterment of the students and the medical school environment. Hence, measures such as

\section{REFERENCES}

1. Poudel A, Gautam S. Age of onset of substance use and psychosocial problems among individuals with substance use disorders. BMC Psychiatry. 2017;17(1):10. PMID: 28077106

2. Khanal P, Ghimire R, Gautam B, Dhungana S, Parajuli P, Jaiswal A, et al. Substance Use among Medical Students in Kathmandu Valley. JNMA J Nepal Med Assoc. 2010;50(180):267-72. PMID: 22049888

3. Pela OA, Ebie JC. Drug abuse in Nigeria.A review of epidemiological studies. Bull Narc 1982;34(3-4):91-9. PMID: 6985029

4. Walters PA, Goethals GW, Pope HG. Drug use and life style among 500 College undergraduates. Arch Gen Psychiatry.1972;26:92-6. PMID: 5009432

5. Hogan MJ. Diagnosis and treatment of teen drug use. Med Clin North Am. 2000;84(4):927-66. PMID: 10928196.

6. Voigt K, Twork S, Mittag D, Göbel A, Voigt R, Klewer J et al. Consumption of alcohol, cigarettes and illegal substances among physicians and medical students in Brandenburg and Saxony (Germany). BMC Health Serv Res. 2009;9(1):219. PMID: 19958534

7. Olashore A, Ogunwobi O, Totego E, Opondo P. Psychoactive substance use among first-year students in a Botswana University: pattern and demographic correlates. BMC Psychiatry. 2018;18(1): 280. PMID: 30170569

8. Budhathoki N, Shrestha MK, Acharya N, Manandhar A. Substance use among third year medical students of Nepal. J Nepal Health Res Counc. 2010;8(1):15-8. PMID: 21879007 proper counseling and student guidance should be taken to address the problem of substance use, so that its prevalence can be significantly reduced, if not completely eliminated.

\section{RECOMMENDATION}

The assessment of knowledge, attitude and practice of the medical students regarding substance use and its pattern needs to be further explored in depth on larger population.

\section{LIMITATION OF THE STUDY}

The study is a single centered study, and the samples represent only medical students of one medical college. Therefore, the finding of this study cannot be generalized at a national level. Multi-sectoral study needs to be conducted in order to understand the use and others factors that influence the use of these substances among medical students. As the present study depends on the information provided by the participants, there is a possibility of recall bias in the study.

\section{ACKNOWLEDGEMENT}

We are thankful to all the staffs of the Department of Forensic Medicine and administration of BMCTH for their help and support.

\section{CONFLICT OF INTEREST}

Authors declare that there is no conflict of interest.

\section{FINANCIAL DISCLOSURE}

None

9. Kjøbli J, Tyssen R, Vaglum P, Aasland O, Grønvold NT, Ekeberg O. Personality traits and drinking to cope as predictors of hazardous drinking among medical students. J stud Alcohol. 2004;65(5): 582-5. PMID: 15536766

10. Arora A, Kannan S, Gowri S, Choudhary S, Sudarasanan S, Khosla PP. Substance abuse amongst the medical graduate students in a developing country. Indian J Med Res. 2016;143(1):101-3.PMID: 26997021

11. Roy R, Roy D, Goit R. Substance Abuse Among Medical Students - A Survey in a Medical College in Nepal. Journal of Nepalgunj Medical College. 2018;16(1):71-5. DOI: https://doi.org/10.3126/ jngmc. v16i1. 24236

12. Shyangwa PM, Joshi D, Lal R. Alcohols and other Substance Use/ Abuse among Junior Doctors and Medical Students in a Teaching Institute. J Nepal Med Assoc. 2007;46(167):126-9. PMID: 18274568

13. Shrestha J, Tiwari S, Kushwaha DK., Bhattarai P, Raj R. Prevalence of Psychoactive Drug Use among Medical Students in a Medical College of Nepal. J Nepal Med Assoc. 2020;58(230):717-20. DOI: https://doi.org/10.31729/jnma.5237

14. Firth-Cozens J. Interventions to improve physicians' well-being and patient care. Soc Sci Med. 2001;52(2):215-22. PMID: 11144777.

15. Kushwaha R, Rauniar GP, Koirala B, Mandal NK. Prevalence of Substance Use among Undergraduate Students in a Medical College of Nepal. JNMA J Nepal Med Assoc. 2019;57(219):315-319. PMID: 32329455 . 